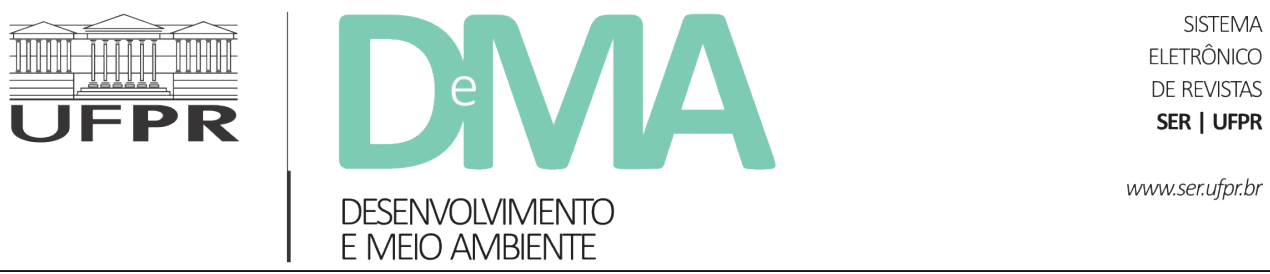

\title{
As Reservas Extrativistas da Terra do Meio: uma experiência de desenvolvimento alternativo para a Amazônia
}

\section{The Extractive Reserves of Terra do Meio: an experience of alternative development for the Amazon}

\author{
André VILLAS-BÔAS ${ }^{1}$, Rodrigo JUNQUEIRA' ${ }^{1}$, Marcelo SALAZAR ${ }^{1}$, Augusto POSTIGO ${ }^{1}$, Jeferson \\ STRAATMANN ${ }^{1}$, Cristina VELÁSQUEZ ${ }^{1}$, Juan DOBLAS ${ }^{1}$, Edione GOVEIA ${ }^{1}$, Maria Augusta TORRES ${ }^{1}$, \\ Victor Cabreira LIMA', Fabíola Andressa Moreira da SILVA ${ }^{1}$, Leonardo de MOURA1, Roberto REZENDE ${ }^{\text {* }}$ \\ ${ }^{1}$ Instituto Socioambiental, São Paulo, SP, Brasil. \\ *E-mail de contato: isaterradomeio@socioambiental.org
}

Artigo recebido em 19 de abril de 2018, versão final aceita em 12 de setembro de 2018.

RESUMO: As reservas extrativistas, um dos legados do movimento organizado dos seringueiros do qual Chico Mendes foi um dos grandes protagonistas, foram idealizadas como proposta de desenvolvimento para Amazônia e para os povos da floresta, alternativa ao modelo estatal hegemônico, de características ambientalmente predatórias e socialmente excludentes. Desde o assassinato de Chico Mendes em 1988 foram criadas 88 reservas extrativistas (sendo 62 federais e 26 estaduais). Três dessas reservas extrativistas federais foram criadas nos anos 2000 na Bacia do Xingu, na região conhecida como Terra do Meio. O presente artigo relata a experiência de organização e gestão dessas reservas, defendendo que o modelo das reservas extrativistas pode realizar os objetivos presentes na idealização de sua proposta pelo movimento de Chico Mendes e demais seringueiros mediante a observação de certas condições, incluídas aí o estabelecimento de parcerias e alianças nos diversos setores da sociedade. Escrevemos da perspectiva de membros do Instituto Socioambiental, organização não governamental parceira e assessora das associações dos moradores das Resex da Terra do Meio, há mais de 25 anos instituição importante em questões socioambientais da Bacia do Xingu. Desse ponto de vista, descreveremos as estratégias que têm sido adotadas pelas famílias e seus parceiros em busca de um desenvolvimento ambientalmente viável e socialmente digno e justo.

Palavras-chave: Reservas Extrativistas; povos tradicionais; ribeirinhos; direitos. 
ABSTRACT: The model of Extractive Reserves in the Brazilian Amazon came out of the struggle of the rubber tappers' social movement led by Chico Mendes. The Reserves model was proposed as an alternative development model for the Amazon and its peoples, in contrast to a hegemonic model based on destruction of the forest and social inequality. Since Chico Mendes' death, 88 Extractive Reserves have been created in Brazil. Three of them were created in the 2000's in the Xingu River basin. This article describes the experience of organization and management of those Reserves, arguing that the model of Extractive Reserves can, under certain circumstances, achieve the goals first conceptualized by the movement led by Chico Mendes. We write as members of Instituto Socioambiental, an NGO that has been working in the Xingu River basin for decades, supporting associations of inhabitants of the Extractive Reserves for more than ten years. We describe strategies that families and partner institutions have chosen in pursuit of a model of development that is environmentally sustainable and socially just.

Keywords: Extractive Reserves; traditional people; river dwellers; rights.

\section{Introdução}

Na segunda metade do século XX, famílias seringueiras de muitas partes da Amazônia passaram a enfrentar pressões e ameaças resultantes de um modelo de desenvolvimento predatório planejado e promovido pelo Estado principalmente a partir do período militar (Hecht \& Cockburn, 1990). A onda desenvolvimentista colocava em risco o modo de vida tradicional das famílias, desenvolvido a partir da chegada dos primeiros migrantes nos seringais (Almeida, 2012).

No Acre, a partir de um movimento organizado por seringueiros vinculados aos Sindicatos de Trabalhadores Rurais de Brasileia e Xapuri, na década de 1970, surge uma alternativa inovadora ao modelo predatório de ocupação da Amazônia. A luta dos seringueiros por seu território, pela floresta como condição de existência de um modo de vida baseado numa economia florestal, pelo fim das derrubadas para criação de gado em Rondônia e leste do Acre, e pelo fim do pagamento da renda aos patrões no oeste acreano resultou, na década de 1980, sob a liderança de Chico Mendes e do
Conselho Nacional dos Seringueiros (CNS $)^{1}$, na proposta de uma "reforma agrária dos seringueiros", baseada no modelo das Terras Indígenas, e cujo objetivo principal era garantir segurança fundiária. As reservas extrativistas foram defendidas por uma fração importante do ambientalismo internacional que acreditava que quem melhor poderia cuidar da floresta era quem dependia dela (Allegretti, 1990; 2008; Almeida, 2004; Schwartzman, 1989).

$\mathrm{Na}$ mesma época em que os seringueiros do Acre e Rondônia se organizaram na luta contra o desenvolvimentismo, na bacia do Xingu, especificamente na cidade de Altamira, movimentos sociais, indígenas e ONGs uniram-se contra a proposta do governo de construir um grande complexo hidrelétrico conhecido como Kararâo, uma sequência de sete barragens a serem implantadas nos Rios Xingu e Iriri. Há anos a região do Xingu vinha sendo impactada com o modelo de ocupação baseado na pata do boi, como a construção da Transamazônica e os subsequentes projetos de colonização públicos e privados que resultaram em concentração de terras e derrubada de florestas para pecuária.

\footnotetext{
${ }^{1}$ Antigo Conselho Nacional dos Seringueiros, hoje renomeado para Conselho Nacional das Populações Extrativistas.
} 
Um dos marcos do enfrentamento contra o desenvolvimento predatório ocorreu em fevereiro de 1989, pouco depois da morte de Chico Mendes. Naquele ano reuniu-se em Altamira (PA) um grande número de povos de diversas etnias indígenas de toda a bacia do Xingu, desde o Mato Grosso, e somando-se a seus parceiros e aliados, notadamente, movimentos sociais locais, ONGs, jornalistas, assessores dos movimentos, pesquisadores e ativistas. O encontro explicitou a ameaça aos territórios tradicionais e potencializou a articulação entre povos indígenas e parceiros na defesa do Xingu e seus povos. As negociações para financiamento internacional do complexo hidrelétrico Kararaô foram suspensas e uma série de ações tomaram curso para o reconhecimento e demarcação de Terras Indígenas na bacia do Xingu. Foramhomologadas as Terras Indígenas Kayapós (Capoto Jarina - 1991, Kayapó - 1991, Mekragnoti - 1993), a Araweté (declarada em 1992 ehomologada em 1996) a Kuruaya (1992), Kararaô e outras, dando contorno ao corredor de áreas protegidas do Xingu.

Ao mesmo tempo em que a demarcação das Terras Indígenas assegurava os direitos territoriais aos povos indígenas do Xingu, nos anos 1990, intensificou-se um grande movimento de saque de mogno nas florestas da bacia, abrindo milhares de quilômetros de estradas que serviram posteriormente à grilagem de terras e ao desmatamento de grandes proporções. Essas áreas ocupadas ilegalmente eram, em sua maioria, áreas não protegidas pelo Estado, embora fossem habitadas por famílias de seringueiros e seus descendentes, então pressionados para abandonar a posse de suas terras.

Essas famílias seringueiras haviam se estabelecido na região, principalmente durante os dois grandes ciclos da borracha (cf. ISA, 2017b, p. 20), quando os patrões seringalistas garantiam uma assistência mínima fundamentada em acordos morais entre as partes. Já os seringalistas legitimavam-se no território por meio de concessões de uso do estado do Pará e de políticas de incentivos nacionais que viabilizavam economicamente os seringais e a própria assistência mínima às famílias. O fim dessas políticas nos anos 1980 levou à inviabilidade econômica do modelo de seringal e, com isso, as famílias da Terra do Meio deixam de contar com a assistência prestada por patrões. No entanto, o Estado não substituiu os patrões no provimento de ações mínimas de saúde e educação, deixando as famílias com redes de assistência e apoio muito fragilizadas (parentes e pequenos comerciantes itinerantes - cf. Almeida, 1992; ISA 2017a).

No vácuo de qualquer política de Estado, e também com a distância em relação ao movimento organizado de seringueiros e organizações de classe como o CNS, a Terra do Meio se tornou, a partir dos anos 1990, alvo de um movimento sistemático de grilagem de terras (ISA, 2015) que, para além do assédio e da violência, apoiou-se na criação de relações de dependência e assistência para legitimar localmente o acesso aos territórios tradicionais. Em outra frente, os grileiros tentavam oficializar direitos sobre as terras. O maior exemplo foi o caso de Cecílio do Rego Almeida, empresário paranaense que, por meio de fraudes em cartórios da região, pretendeu converter essas antigas concessões de exploração de seringa em títulos definitivos de terra, pretendendo-se dono de um latifúndio estimado em sete milhões de hectares. A área englobava significativa parte da Terra do Meio, do rio Xingu até o Riozinho do Anfrísio, a noroeste.

A movimentação da grilagem gerou uma série de denúncias dos movimentos sociais locais e uma 
articulação de organizações da sociedade civil. Já na virada dos anos 2000, o Movimento pelo Desenvolvimento da Transamazônica e Xingu (MDTX), que atuava na região desde a década de 1970, o próprio ISA, a Comissão Pastoral da Terra-Xingu e a Fundação Viver, Produzir e Preservar (FVPP) juntaram-se em defesa das florestas e dos povos da Terra do $\mathrm{Meio}^{2}$, com demandas que encontraram respaldo, em 2002, na Secretaria de Coordenação da Amazônia do Ministério do Meio Ambiente, que acolheu a proposta de encomendar a partir do Ministério do Meio Ambiente um estudo de viabilidade para a criação de um mosaico de unidades de conservação na Terra do Meio.

O ISA assumiu a coordenação do estudo, realizando um diagnóstico socioeconômico dos beiradeiros, como se autodenominam as famílias que descendem dos seringueiros e que hoje habitam, em sua grande maioria, as beiras dos rios. $\mathrm{O}$ estudo mapeou a situação de ameaça e exclusão vivida pelos beiradeiros, sua história e territorialidade, propondo, ao fim, a criação de três reservas extrativistas, uma Estação Ecológica, um Parque Nacional, uma Floresta Estadual e uma Área de Proteção Ambiental (ISA, 2003), que comporiam o Mosaico da Terra do Meio (embora essas unidades de conservação tenham sido criadas nos anos seguintes, a figura do mosaico nunca foi oficializada). Nesse período, especialmente no Riozinho do Anfrísio, um dos afluentes do Iriri, a grilagem e as ameaças aos moradores resistentes a ela estavam em momento crítico.

Com a pressão, as comunidades do Riozinho do Anfrísio também iniciaram um movimento or- ganizado para lutar pela defesa de seus territórios. Essa organização levou à criação da Associação dos Moradores da Reserva Extrativista Riozinho do Anfrísio (Amora), criada antes da reserva extrativista e tendo-a, naquele momento, como principal objetivo. Dentre algumas lideranças comunitárias, Herculano Porto de Oliveira foi escolhido para ser o primeiro presidente da Associação. Pesou na escolha o fato dele ser a única liderança que, na ausência do Estado na região, tinha $\mathrm{CPF}$ e $\mathrm{RG}$, tirados num período de sua vida que passou na cidade na casa de seus tios. Junto a duas outras lideranças locais, Raimundo Belmiro e Luis Augusto Conrado (Manchinha), Herculano viajou a Brasília para pressionar pela criação da reserva e o fim da exploração madeireira intensa que assolava o Riozinho do Anfrísio. Em Brasília, reuniram-se com a então ministra do Meio Ambiente e antiga seringueira do movimento acreano, Marina Silva, que apoiou a articulação da criação da reserva junto à presidência (Lima, 2015) ${ }^{3}$.

As ações de grilagem e saque começaram a ser aplacadas com o decreto da Reserva Extrativista Riozinho do Anfrísio, em 2004, seguida pela presença continuada da Força Nacional na localidade do então presidente da associação de moradores. Em 2005, após a pressão política decorrente do assassinato da missionária Dorothy Stang, as outras UCs propostas foram decretadas, com exceção da Resex Rio Xingu. Esta foi decretada somente em 2008, depois de muita briga e uma mudança importante nos planos de barragens para o Rio Xingu. Em abril daquele ano o governo anunciou um recuo do projeto do complexo Kararaô, já renomeado para Belo Monte, e que previa a construção de uma única

\footnotetext{
${ }^{2}$ Para mais detalhes sobre a luta e a história das áreas protegidas do Xingu conferir Schwartzman et al. (2013), e Velásquez et al. (2006).

${ }^{3}$ Marina Silva também havia dado uma autorização prévia para que Raimundo Belmiro e Luis Augusto Conrado pudessem embarcar em um avião sem ter qualquer tipo de documentação.
} 
barragem. Em junho do mesmo ano foi decretada a Resex Rio Xingu, que abarcava a área prevista para uma das barragens do projeto inicial do complexo ${ }^{4}$.

Criadas as reservas extrativistas, o desafio tornou-se implementar políticas públicas para saúde, educação, comunicação, transporte e geração de renda. Era preciso a articulação entre comunidades e instituições governamentais e não governamentais para pensar modelos alternativos para garantia de direitos em um território tão vasto e com comunidades dispersas. Em meio à organização pela garantia de direitos, estava também em jogo provar a viabilidade social, econômica e ecológica do modelo das reservas extrativistas que, desde sua criação, vinha sofrendo críticas tanto pelo modelo de propriedade da terra e a eficácia da gestão coletiva de recursos por parte de povos tradicionais ${ }^{5}$ como pela viabilidade econômica da produção extrativista nos moldes tradicionais na Amazônia, que seria um entrave ao uso mais eficiente da terra ${ }^{6}$.

Neste trabalho defendemos que o modelo das reservas extrativistas continua uma alternativa econômica e ecológica viável para povos tradicionais da Amazônia. Tanto os seringueiros do Acre como os do rio Xingu enfrentaram a expansão de atividades predatórias sob a floresta, que fazem parte de um movimento histórico de expansão das fronteiras capitalistas que se convencionou denominar desenvolvimentismo. Nesses contextos, as reservas extrativistas surgiram como a reforma agrária que deu garantia territorial, ao mesmo tempo em que estabeleceu compromissos com o Estado para a conservação da natureza. Os seringueiros acreanos e os moradores da bacia do Xingu tiveram que lidar com desafios semelhantes, em especial o de aliar o desenvolvimento social, a melhoria da qualidade de vida nos mais diferentes aspectos, com a conservação e a manutenção da floresta em pé. Embora alguns esperem que essas sejam consequências naturais da criação das reservas extrativistas, esses objetivos demandam das famílias uma capacidade para a gestão coletiva de grandes áreas além de suas tradicionais colocações, o enfrentamento das pressões no entorno de seus territórios, a construção de políticas públicas adequadas à sua realidade, e a garantia de renda e melhores condições de vida a partir da valorização de seus produtos pelo mercado e sociedade envolventes.

Nessa perspectiva, o Instituto Socioambiental (ISA) tem trabalhado há mais de 10 anos na região da Terra do Meio, com o objetivo de consolidar as reservas extrativistas como modelo de desenvolvimento. Esse trabalho inclui a estruturação de cadeias produtivas associadas aos produtos tradicionais, a organização de associações locais, a busca por melhorias no acesso a serviços básicos de cidadania e a formação de maneira ampla das famílias para a gestão de seus territórios e para uma relação mais simétrica com a sociedade envolvente e um mercado que, via de regra, entende a floresta como recurso a ser predado, e não, como é, para indígenas e beiradeiros, território, morada, história e condição de existência. Todas essas frentes são tomadas como interdependentes e fundamentais para o sucesso da experiência de desenvolvimento que acreditamos em curso nas Reservas Extrativistas da Terra do Meio.

\footnotetext{
${ }^{4}$ Posteriormente à criação das UCs, ações judiciais do Ministério Público Federal desmontaram completamente a farsa dos títulos da CR Almeida.

${ }^{5}$ Em parte influenciados pelo artigo de Garret Hardin sobre recursos comuns (cf. Castillo, 1995).

${ }^{6} \mathrm{Cf}$. Homma, 2012. Um balanço com mais críticas e uma defesa do modelo das reservas extrativistas pode ser encontrado no artigo "O legado de Chico Mendes: êxitos e entraves das Reservas Extrativistas" neste mesmo volume.
} 


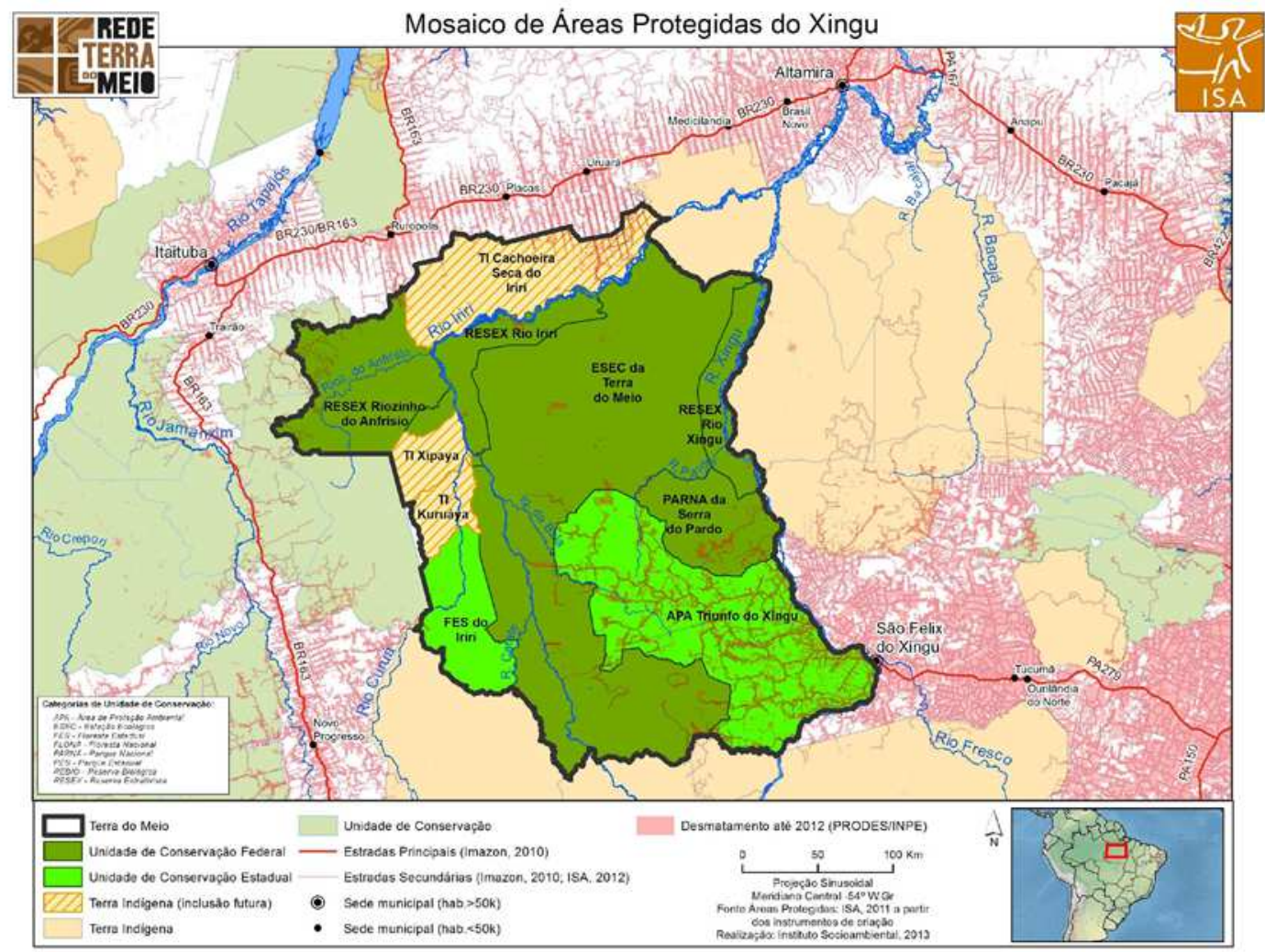

FIGURA 1 - Mosaico de áreas protegidas da Terra do Meio.

\section{As condições para o desenvolvimento alternativo}

A figura das reservas extrativistas havia sido elaborada pelo movimento dos seringueiros e a Aliança dos Povos da Floresta nos anos 80 como forma de garantir o direito territorial para o desenvolvimento do modo de vida das colocações e da florestania ${ }^{7}$. Embora não tivessem participado das lutas organizadas pelo movimento liderado por
Chico Mendes, as famílias da Terra do Meio logo se identificaram com a proposta das reservas extrativistas, criando e compreendendo rapidamente a conexão do modelo de gestão territorial com sua história e modo de vida. As famílias também sabiam que a criação das Reservas Extrativistas da Terra do Meio seria o primeiro passo para a estruturação de uma gestão do território que lhes garantisse uma vida digna e que corrigisse a violência, o descaso e o abandono vivenciado nas décadas anteriores.

${ }^{7} \mathrm{O}$ conceito de florestania foi desenvolvido pelo jornalista e escritor Antonio Alves e sintetizava os ideais do movimento de seringueiros a uma vida digna na floresta, similar à cidadania das cidades. Sobre o modelo das colocações, ver Almeida (2012). 
Para tanto, era preciso políticas coordenadas entre vários atores e níveis de governo (Velásquez et al., 2006). Antes das Reservas, por exemplo, o índice de analfabetismo passava dos $80 \%$ e a maioria dos moradores da região sequer possuía documentação cidadã. Não havia qualquer serviço de saúde do Estado que atendesse às famílias, cujo único recurso era buscar apoio em territórios indígenas vizinhos ou enfrentar difíceis viagens para Altamira. A comunicação com a cidade e o mercado era precária e realizada por intermédio de regatões, que proviam também meios de transporte em uma região na qual o deslocamento das localidades beiradeiras até Altamira pode levar mais de uma semana, a depender das condições dos rios.

É nesse contexto que o ISA, em 2006, toma a decisão institucional de apoiar as organizações dos beiradeiros da Terra do Meio, investindo em uma estratégia de longo prazo para estruturar o acesso a direitos básicos de cidadania, consolidar infraestrutura de transporte e comunicação, atrair assistência do Estado e formar uma geração de pessoas para lidar com os desafios de gestão das Resex nos aspectos territorial e associativista. Era um conjunto de ações necessárias ao desenvolvimento dessas áreas como territórios que, ao mesmo tempo, conjugasse maior articulação e protagonismo político com a conservação e a melhoria das condições de vida, tal qual imaginada pelos beiradeiros ${ }^{8}$. A implementação dessas ações estratégicas envolveu o empenho institucional na captação e investimento de recursos e na consolidação de uma equipe local multidisciplinar, amparada por mais de duas décadas de experiência do ISA na bacia do Xingu e no trabalho com povos indígenas, e que passou a pensar junto aos beiradeiros a implementação de direitos e serviços de maneira adequada à dispersão tradicional das famílias e seus modos de vida, algo que as instituições de Estado não sabiam como lidar. Para a instituição, estavaclaro desde o início que o sucesso de um modelo de desenvolvimento pautado em uma economia florestal abrigado nas reservas extrativistas dependeria de algumas condições que deveriam se articular: o respeito aos modos de vida tradicionais em qualquer modelo de gestão ou produção; a estruturação de associações fortes e que funcionem em parceria com outras instituições; assistência técnica para produção e melhoria de renda; formação para gestão ${ }^{9}$; apoio financeiro e; políticas públicas adequadas aos modos de vida tradicionais e à proteção de vastos territórios.

\section{Associações fortalecidas}

A organização das associações iniciou-se antes mesmo da primeira reserva extrativista, a Riozinho do Anfrísio, criada por decreto presidencial $\mathrm{s} / \mathrm{n} .^{\circ} \mathrm{em}$ 08 de novembro de 2004. Em março daquele ano havia sido criada a Associação dos Moradores da Reserva Extrativista Riozinho do Anfrísio (Amora). Após dois anos, os moradores do Rio Iriri, inspirados pelos vizinhos, também se organizaram para demandar a criação de uma reserva extrativista. Assim se criou a Associação dos Moradores do

\footnotetext{
${ }^{8} \mathrm{O}$ ISA atua em diferentes regiões do país, focando a ação no território junto a povos tradicionais e no recorte de bacias, com equipes multidisciplinares que abordam fenômenos socioambientais a partir de diferentes ângulos e com linhas de trabalho planejadas no longo prazo, tornando o financiamento por projetos o meio e não o fim das ações planejadas junto aos povos. Quando iniciou e estruturou seu trabalho na Terra do Meio, o ISA já atuava na bacia do Xingu há mais de 14 anos.

${ }^{9}$ Formação para gestão, tal qual praticada pelo ISA nesse contexto, significa instrumentos e conteúdos necessários e demandados para lidar com a sociedade envolvente de forma protagonista.
} 
Rio Iriri, que após a criação da Resex (decreto $\mathrm{s} / \mathrm{n}$. ${ }^{\circ}$ de 05 de junho de 2006) passou a ser a Associação dos Moradores da Reserva Extrativista Rio Iriri Amoreri.

Além de criar as associações, era preciso que os moradores como um todo passassem a participar de espaços decisórios e pudessem estabelecer uma relação protagonista com novas instituições e atores que chegavam ao território a partir da criação da reserva extrativista e da luta por direitos. Para isso, houve ações para promoção de ampla participação em assembleias e garantia de entendimento da estrutura de uma associação. Aos poucos, as assembleias foram também se tornando espaços de pressão e cobrança por melhores condições de educação e saúde, além de outras demandas como comunicação e transportes.

Como estratégia para pressionar o Estado por condições básicas de saúde e educação, as associações e instituições parceiras adotaram a estratégia de captar recursos para a construção de polos de integração e desenvolvimento dentro das três Resex. Esses polos deveriam ter uma estrutura mínima: unidade básica de saúde, com casa para enfermeiro; centro de formação/escola, com alojamento para os alunos e casa para professores; núcleo de apoio às associações locais e parceiros; estrutura de armazenamento e beneficiamento da produção extrativista local; aparato de comunicação, com internet e telefone público para complementar o sistema de rádios que já operava na região; e, por fim, pistas de pouso, destinadas a facilitar assistência emergencial, mutirões de atendimento especializado à saúde e ações de proteção e fiscalização, bem como propiciar a articulação com órgãos da administração e com outros parceiros.
A partir da construção dos polos foi possível gerar centralidade para o atendimento das famílias, cuja ocupação territorial é dispersa, e articular entre as associações locais e secretarias municipais da prefeitura de Altamira o envio e manutenção de equipamentos e profissionais para que os direitos mínimos à saúde e educação fossem mantidos nesses locais. Os polos também propiciaram centralidade na comunicação com Altamira (por meio dos rádios instalados) e se tornaram referência para assistência técnica e parcerias comerciais. Para evitar que os polos se tornassem centros de atração e concentração de famílias (como ocorreu em outros locais da Amazônia, cf. Costa, 2010; Rezende, 2010), houve também um processo de criação de núcleos menores em outras localidades, garantindo acesso à educação fundamental básica às famílias sem que elas precisassem se mudar para as localidades polos.

Todo esse processo de lutas por direitos foi deixando claro que, para obter os resultados esperados, era preciso uma articulação em vários níveis, a começar por uma organização local forte e articulada. Nesse sentido, um dos primeiros passos foi adotar a estratégia de luta conjunta das associações das três reservas extrativistas, firmando termos de cooperação para partilha de ações e projetos.

Desde 2016 as associações mantêm um assessor comum remunerado em Altamira, quecoordena as questões que precisam ser resolvidas na cidade entre os diferentes atores. Também fazem parte da equipe das associações uma assistente social e três assessores comunitários remunerados (jovens escolhidos pelas comunidades). São fundamentais também as instituições de apoio, que ajudam a assegurar condições de vida dignas e segurança fundiária para as famílias. Por exemplo, ISA e FVPP juntaram 
esforços nos anos iniciais das reservas extrativistas para garantir o acesso das famílias beiradeiras a direitos básicos. Outro exemplo foi a cooperação técnica entre o ISA, o Ministério Público Federal (MPF) e o Instituto Brasileiro do Meio Ambiente e dos Recursos Naturais Renováveis (Ibama) para promover a segurança fundiária, buscando retirar os grileiros do mosaico de áreas protegidas. Essas articulações ocorreram no âmbito da Rede Terra do Meio, formada por um conjunto de instituições dispostas a apoiar os moradores e a consolidação de um mosaico, e que operava em reuniões anuais ${ }^{10}$. A Rede dividia-se em grupos de trabalho temáticos, como proteção territorial ou produção e comercialização ${ }^{11}$, e teve papel fundamental nos primeiros anos de implementação das políticas para as unidades de conservação.

Como resultado, após pouco mais de uma década de ações, é possível observar que as Resex deixaram a situação de abandono para uma vivência com maior presença do Estado e com o fortalecimento e estabelecimento de novas parcerias. São 216 famílias morando nas Resex ${ }^{12}$, distribuídas em 83 localidades e atendidas por 23 escolas e três unidades básicas de saúde em funcionamento (e mais duas já construídas). Esse novo contexto encorajou, nos anos posteriores à criação das Resex, o retorno de algumas famílias que tinham saído dos territórios tradicionais em busca de educação e empregos em Altamira.

\section{Assistência técnica para produção}

Paralelamente à estruturação das associações para a luta de acesso a direitos básicos, houve um grande esforço dos moradores e das instituições parceiras para a estruturação de cadeias de produtos da floresta. Conseguir uma renda digna convivendo com a floresta era condição para permanência das famílias no território ao longo dos anos. Três apontamentos principais das famílias beiradeiras sobre o que precisava mudar nortearam as ações: aumentar a renda, a partir da melhoria do preço e da qualidade dos produtos locais; firmar contratos de longo prazo que garantissem segurança e planejamento aos produtores; e evitar exigências contratuais que fossem conflitantes com o modo de vida tradicional.

Com esses princípios em mente, foi realizado em 2008 um diagnóstico preliminar para identificar as condições de produção e comercialização dos produtos florestais não madeireiros (ISA, 2008), seguido de uma avaliação das principais cadeias de produtos da sociobiodiversidade nas três reservas extrativistas (Imaflora \& ISA, 2010a; 2010b; 2010c). Uma das primeiras constatações foi a de que a gestão da produção ocorria essencialmente na esfera familiar e baseada numa lógica de múltiplos produtos. Alguns deles eram voltados exclusivamente para a comercialização (como a borracha), outros para consumo e venda (como a castanha) e outros apenas para o consumo (como as frutas de

\footnotetext{
${ }^{10}$ Formavam a Rede associações de moradores das unidades de conservação e do entorno, FVPP, ICMBio, Ideflor, IIEB, Imaflora, ISA, secretarias de educação e saúde de Altamira, UFPA, dentre outras.

${ }^{11}$ Do grupo de trabalho de produção e comercialização surgiria a ideia da realização da Semana do Extrativismo, um dos eventos centrais para a organização das cadeias produtivas da Terra do Meio.

${ }^{12}$ De acordo com dados oficiais de 2009, provenientes dos Planos de Manejo das três reservas extrativistas (disponíveis em: < http://www.icmbio. gov.br/portal/unidades-de-conservacao $>$ ).
} 
roças e quintais). À época, os itens comercializados dependiam das demandas trazidas por regatões, que operacionalizavam boa parte das conexões com os mercados.

Dentre os produtos comercializados com regatões, destacava-se o peixe no gelo, destinado ao abastecimento da cidade de Altamira e arredores, e que representava a maior parte da renda proveniente da produção durante grande parte do ano. Outro produto essencial era a castanha-do-pará, que sempre foi uma atividade bastante absorvente nos meses de safra, de dezembro a abril. Igualmente por intermédio dos regatões, a produção de castanha dirigia-se para poucos compradores em Altamira, com destino a grandes beneficiadores que, por sua vez, repassavam-na a mercados nacionais ou internacionais de maior porte. Havia ainda a borracha, historicamente a atividade extrativista mais importante das bacias do Xingu e Iriri, que, em 2008, era comercializada de forma quase residual por poucas famílias da Resex Riozinho do Anfrísio junto a regatões que abasteciam um único atravessador, que a revendia para fabricação de pneus por preços irrisórios. Quem seguia cortando seringa nessa época o fazia menos por retorno financeiro imediato do que pela manutenção do modo de vida. "Todos aqui foram criados na borracha", lembrava um beiradeiro. Outros produtos eram fonte de renda, mas de maneira menos significativa e frequente, como a farinha de mandioca e os óleos vegetais (como os de babaçu, patoá, andiroba).

Diante desse quadro, o trabalho de estruturação priorizou aquelas cadeias que pudessem ser trabalhadas por um grande número de famílias e que não encontravam venda garantida em volumes significativos. Além disso, buscavam-se atividades que tivessem sustentabilidade na forma corrente de sua produção, ao mesmo tempo em que se baseassem no fortalecimento do modelo tradicional de ocupação do território, as colocações (Almeida, 2012; Postigo, 2012), e nos conhecimentos a ele associados. Desde o início a borracha recebeu atenção especial, tanto porque a prática de extração do látex estava imbricada na identidade beiradeira como porque havia uma geração inteira que não sabia mais como produzir borracha. Retomar a viabilidade econômica da borracha era também uma forma de retomar a história e a identidade seringueira das famílias. Aos poucos, a retomada da borracha tem dado frutos. Após alguns anos de envolvimento de antigos seringueiros na atividade, alguns jovens começam a aprender o ofício, garantindo a continuidade da atividade e dos conhecimentos associados ${ }^{13}$.

Outro desafio da estruturação era conciliar diferentes atividades produtivas ao longo do ano, garantindo alternativas de renda de maneira constante. Por exemplo, intercalando a safra da castanha, de dezembro a abril, com a da seringa, de maio a novembro ${ }^{14}$. E também deveria haver outras fontes de renda durante as safras, respeitando o princípio de garantir opções de trabalho e renda às famílias. Seja porque elas geralmente têm muitos trabalhadores, que podem se dedicar a atividades simultâneas, ou porque as famílias e os indivíduos têm preferências e predisposições por determinadas atividades. Assim, enquanto parte do grupo familiar pode se

\footnotetext{
${ }^{13}$ Entre 2009 e 2017, os incentivos para a produção de borracha elevaram a produção de duas para oito toneladas de borracha em bloco, aliados ao desenvolvimento em parceria com a Mercur da técnica de produção de manta de borracha sem uso de ingredientes químicos nocivos ao ambiente, que em 2017 representou $650 \mathrm{~kg}$.

${ }^{14}$ Para o calendário anual completo de atividades tradicionais, ver a publicação Terra do Meio/Xingu: os saberes e práticas dos beiradeiros do Rio Iriri e Riozinho do Anfrísio (ISA, 2017b).
} 
dedicar a uma ida para os castanhais, outra parte pode se dedicar a uma expedição na floresta em busca de copaíba. Ou então na produção de farinha de babaçu, que envolve deslocamentos menores pela floresta e pode ser feita nos arredores das casas, envolvendo mais mulheres e crianças, por exemplo.

Identificadas as cadeias prioritárias, as organizações parceiras, em especial Imaflora e ISA, foram atrás de empresas que comprassem a produção local com um entendimento das especificidades das cadeias (produtivas e logísticas) e dos modos de vida tradicionais. A primeira parceria comercial de longo prazo estabelecida na Terra do Meio foi com a empresa Mercur, em 2010, para a compra de borracha ${ }^{15}$. Após uma primeira reunião de aproximação entre Mercur, Imaflora e ISA, o passo seguinte foi a visita de um gerente da Mercur ao Riozinho do Anfrísio e ao rio Iriri, para uma série de conversas com as comunidades e o estabelecimento das bases de um acordo de comercialização satisfatório para as duas partes. Uma sequência de encontros se sucedeu até se consolidar a parceria, durante os quais se discutiram abertamente temas como a transmissão do conhecimento tradicional associado à floresta e o envolvimento de crianças e adolescentes na dinâmica de trabalho familiar; as condições mínimas de organização e remuneração da produção; o aprimoramento de processos; e a formalização do contrato de comercialização. Esses diálogos seguem ocorrendo mesmo após anos de parceria e são fundamentais para que o mundo da empresa permaneça conectado ao da floresta e vice-versa. Os diálogos incluem visitas de seringueiros à sede da empresa no Rio Grande do Sul, ao processador intermediário da borracha (a QR Borrachas Quirino) e visitas dos representantes da Mercur às comunidades beiradeiras ${ }^{16}$.

Nos anos seguintes, o modelo de parceria e comercialização estabelecido com a Mercur foi reproduzido e adaptado na relação com outras empresas, diversificando os contratos. Vieram os contratos para compra de copaíba (com a empresa Firmenich, em 2011), de castanha-do-pará (Ouro Verde, em 2012, e Wickbold, em 2015, Fundação Somos Um, 2018), artesanato (Tucum, em 2016), e cumaru (Lush, em 2017). O Imaflora e o ISA, por meio do Selo Origens Brasil ${ }^{17}$, tiveram um papel fundamental na aproximação dessas parcerias comerciais com as associações locais.

Junto aos primeiros contratos foi preciso estruturar a cadeia de comercialização e abastecimento das famílias para as safras. Como diziam os beiradeiros, era preciso criar um sistema semelhante ao dos barracões dos seringais, em que fosse possível vender a produção e obter itens da cidade. Para isso, foram criadas cantinas comunitárias, onde as famílias de produtores pudessem adiantar mercadorias durante as safras e depois entregar sua produção, recebendo eventuais saldos. $\mathrm{O}$ grande diferencial das cantinas da Terra do Meio em relação aos barracões dos patrões, ou aos comércios da cidade, é que, seguindo a inspiração dos seringueiros do Acre, a cantina e o capital de giro não são recursos

\footnotetext{
${ }^{15} \mathrm{O}$ contato com a Mercur foi estabelecido ao se saber que a empresa buscava parcerias comerciais com comunidades dentro de uma lógica de reestruturação de ações pela qual passava a empresa como um todo, e que tinha como uma de suas diretrizes a atuação em "mercados éticos, que valorizam a vida". Mais informações sobre a proposta de reestruturação das ações da Mercur podem ser encontradas em: $<$ http://www. mercur.com.br/institucional\#responsabilidades>.

${ }^{16}$ Para um relato mais detalhado das negociações com empresas, conferir a publicação Xingu: histórias dos produtos da floresta (ISA, 2017a).

${ }^{17}$ Mais informações sobre o selo Origens Brasil podem ser obtidas em http://www.origensbrasil.org.br/ (acessado em agosto de 2018)
} 
privados, mas fundos gerenciados coletivamente, cuja finalidade também é coletiva: garantir, tal como no sistema de aviamento (Weinstein, 1993), que os extrativistas sejam abastecidos de mercadorias para si e sua família no início e durante o processo de coleta. Em outras palavras, a inovação fundamental do sistema de cantinas com capital de giro consiste em deslocar o financiamento da produção das mãos do regatão ou patrão para as dos próprios produtores. Além disso, a proposta também implica maior controle sobre os preços das mercadorias, por meio da compra direta nas cidades.

Para que esse sistema funcionasse de maneira adequada foi preciso garantir um capital de giro que aviasse os produtores durante as safras. A partir de projetos das associações no âmbito do Plano de Desenvolvimento Regional Sustentável do Xingu e de doações de empresas parceiras e apoio e empréstimos do ISA às associações, foi formado e anualmente incrementado um montante de capital de giro que permite às famílias tomarem mercadorias adiantadas nas cantinas. Hoje, esse capital de giro é descentralizado e cada cantina e comunidade de produtores têm independência sobre a administração dos recursos. Também se buscou nas cadeias produtivas promover uma relativa independência no tocante a contextos políticos, com a descentralização do capital de giro e sua vinculação ao cantineiro e seu grupo de vizinhança. A gestão desse capital requereu, e ainda requer, uma série de conversas com as famílias sobre a origem e a natureza do dinheiro e sobre como o "giro" do capital permite abastecê-las com mercadorias e comprar a produção, e que, se grande parte do capital de giro for emprestado na forma de fiado, ele estará imobilizado para fazer fluir a cadeia ${ }^{18}$. A compreensão do funcionamento do capital de giro é parte do princípio de que todos devem entender as cadeias em seus diversos elos, tornando-as transparentes em sua integridade, da produção ao consumidor final, de modo a aprimorar o sistema de tomada de decisões.

Outro nível de assistência técnica se refere aos produtores. Além do sistema comercial adequado aos modos de vida, é preciso que os produtores observem boas práticas para que sua produção tenha a qualidade necessária às parcerias comerciais. Isso envolve visitas constantes aos produtores para debater processos e manejo dos produtos de acordo com orientações técnicas das empresas parceiras, em um movimento constante de diálogo e ajustes assessorado pela equipe do ISA.

Estruturadas as primeiras cadeias, o ISA passou a apoiar tecnicamente os moradores na construção de unidades de beneficiamento e processamento de produtos da floresta, chamadas miniusinas. As miniusinas são espaços com um conjunto de equipamentos com tecnologias apropriadas para o processamento de vários gêneros florestais, adaptadas ou desenvolvidas a partir da união de saberes tradicionais e técnico-científicos, e permitindo o processamento de dezenas de produtos

\footnotetext{
${ }^{18}$ Experiências anteriores de cantinas e cooperativas enfrentaram dificuldades de gestão por colocar os gerentes em uma difícil situação: a de administrar o capital de giro frente à pressão redistributiva imposta pelas relações econômicas e políticas tradicionais, que por vezes resultava em grandes montantes de recursos imobilizados na forma de crédito (cf. Pantoja, 1994, p. 195; Costa, 2010, p.221-22). O fiado foi controlado em parte por meio de um processo contínuo de reuniões com as comunidades para que compreendessem a importância do capital de giro estar nas mãos dos cantineiros, e não imobilizado em empréstimos, sob o risco de inviabilizar as próprias safras.

${ }^{19}$ Como sistemas eletrônicos de desidratação com potencial para castanhas, pimentas e frutas; secagem de sementes para processamento de óleos no mesmo equipamento em que é possível torrar farinhas e doces de fruta; extração de óleos com extratora helicoidal adaptada para funcionar com os mesmos motores usados nos barcos regionais; desumidificação e redução de temperaturas de ambientes para estocagem de sementes e outros produtos, dentre outras.
} 
da floresta ${ }^{19}$. Atualmente há quatro miniusinas construídas nas unidades de conservação da Terra do Meio. Pela versatilidade de equipamentos e processos produtivos, elas possibilitam lidar com grande variedade de produtos, permitindo equacionar épocas de safras, aptidões diferenciadas, regionalidades, variações de preço e disponibilidade de contratos ${ }^{20}$. Além de diversificar os produtos, as miniusinas agregam valor aos produtos florestais no interior das próprias comunidades.

Toda a gestão do arranjo produtivo em sua integridade depende de espaços decisórios nos diferentes níveis das cadeias. Para isso foi criada uma estrutura de encontros para dar conta das complexidades de gestão em cada um desses níveis. A começar pelas reuniões de cantina (nível local), o encontro dos cantineiros (regional)e a semana do extrativismo (global, no sentido da integridade das cadeias).

As reuniões de cantinas são realizadas em cada localidade que tem uma cantina, congregando os produtores atendidos por ela, cantineiros e a equipe técnica de organizações parceiras ${ }^{21}$. Nessas ocasiões, o grupo debate e decide sobre uma série de aspectos do funcionamento das cantinas, como o preço das mercadorias, os termos de cooperação com empresas, medidas para auferir e controlar a qualidade da produção, o gerenciamento do capital de giro, logística e custo etc. Cada cantina pode tomar decisões individuais sobre esses aspectos, garantindo um controle e uma participação maior pelos produtores atendidos.

O encontro dos cantineiros (que, mais tarde, seria renomeado para Encontro da Rede de Cantinas e Miniusinas da Terra do Meio) foi idealizado como um espaço anual de troca de experiências e formação entre cantineiros para a gestão de estoques, capital de giro, logística, armazenamento e diversos outros aspectos envolvidos no arranjo produtivo. Por exemplo, trocam informações sobre como suas comunidades decidiram enfrentar a questão do fiado, ou um capital de giro incompatível com a produção do ano. Ou ainda, como determinada cantina se saiu na experiência de tentar comprar e vender produtos localmente, sem o amparo dos contratos. Assim, o encontro torna-se um espaço de pensar possibilidades para novas formas de gestão. Também é no encontro que os cantineiros se articulam para fazer compras de mercadorias coletivamente, ganhando poder de negociação nos comércios locais e reduzindo os custos de frete para suas localidades. Reunir os cantineiros de vários locais para tratar de problemas comuns também fez com que o encontro fosse se tornando um espaço de discussão sobre os territórios tradicionais como um todo e sobre os direitos de acesso das comunidades a eles ${ }^{22}$.

Por fim, outro encontro estruturante para a gestão do modelo comercial é a Semana do Extrativismo, um evento anual que reúne produtores, cantineiros, representantes das associações locais,

\footnotetext{
${ }^{20}$ Um exemplo dessa versatilidade pode ser observado na safra de 2016, na miniusina do Rio Novo, onde foram processados 1.880 quilos de castanha, 84 quilos de farinha de castanha, 309 quilos de óleo de castanha e 100 quilos de mesocarpo de babaçu, além da produção de bolsas e sacos encauchados (revestidos com látex), vendidos localmente. Oito famílias participaram diretamente do processamento e 14 foram envolvidas na coleta dos produtos na floresta.

${ }^{21}$ No caso das cantinas das Resex, o principal parceiro é o ISA. Os estabelecimentos indígenas, por sua vez, contam com o apoio da ONG The Nature Conservancy (TNC), da Fundação Nacional do Índio (Funai) e de empresas contratadas pelo consórcio de Belo Monte, no âmbito de compensações previstas no Plano Básico Ambiental (PBA).

${ }^{22}$ Um exemplo de restrição aos territórios tradicionais em função da criação de unidades de conservação de proteção integral pode ser encontrado em Alarcon \& Torres (2014).
} 
instituições parceiras, parceiros comerciais já existentes e potenciais, e representantes dos diferentes níveis governamentais relacionados às cadeias. Os três primeiros dias do encontro são destinados a uma avaliação estratégica dos arranjos, reunindo somente os cantineiros, os representantes das associações locais, beiradeiros interessados na discussão, o Instituto Socioambiental (ISA) e o Instituto Chico Mendes de Conservação da Biodiversidade (ICMBio). Esse segmento do encontro culmina com um planejamento, que, por sua vez, é apresentado na etapa seguinte, quando chegam os demais participantes (outros órgãos de governo, ONGs e empresas). Essa apresentação consiste em expor o ponto de vista das famílias sobre a forma que entendem como a mais adequada para desenvolvimento da produção. Além disso, os dois últimos dias voltam-se a uma apresentação prática e ilustrativa da experiência dos extrativistas na coleta e beneficiamento dos produtos da floresta. Como apontaram diversos beiradeiros, esse tipo de intercâmbio "valoriza nossa produção porque as empresas percebem o trabalho e o conhecimento que temos", gerando maior confiança entre todas as partes interessadas e fortalecendo o arranjo produtivo local ${ }^{23}$.

As cantinas, os encontros de gestão, e os encontros de negociação talvez não sejam inovações apresentadas pelo arranjo que se estruturou na Terra do Meio. A novidade da experiência reside em outro aspecto: implementar essas atividades de maneira concatenada e paulatinamente, tornando o processo de estruturação comercial também parte de um propautar a atuação do conjunto de parceiros junto ao

cesso mais amplo para a formação de quadros para a gestão dos territórios em diversos níveis.

\subsection{Formação para gestão}

A sustentabilidade das associações e do arranjo produtivo depende do protagonismo das famílias beiradeiras, pensado a partir da apropriação e do entendimento crescente dessas instituições e processos. O entendimento do funcionamento das parcerias comerciais e das leis das reservas extrativistas, por exemplo, demanda muito tempo de debate, observação e vivência com esses novos atores.

Como dito, a maior parte dos beiradeiros não teve acesso à educação formal. Após a criação das reservas era preciso tanto melhorar o acesso a noções básicas de escrita e matemática como ao conjunto de leis e dispositivos jurídicos que garantiam o direito de povos e comunidades tradicionais a seus territórios e a um modo de vida próprio. Isso implicava também uma discussão sobre identidade das famílias beiradeiras, recuperando a história dos seringueiros e as peculiaridades do modo de vida da região.

Com esses objetivos em mente, criou-se o Curso de Gestão Territorial da Terra do Meio. Nele, juntavam-se moradores das três reservas extrativistas e do entorno, para módulos de uma semana, intercalados com visitas às casas dos estudantes nos meses seguintes. Com coordenação do ISA e apoio da FVPP, ICMBio e UFPA, entre 2011 e 2016, foram realizados 10 módulos do curso, abarcando conteúdos amplos como saúde, educação, proteção territorial e organização comunitária, além de matérias específicas, como a história e a geografia da

${ }^{23}$ Para uma descrição detalhada de todo o processo de estruturação das cadeias de produtos florestais na Terra do Meio, ver a terceira parte da publicação Xingu: histórias dos produtos da floresta (ISA, 2017a). 
região ou métodos de organização de cadeias produtivas e operações matemáticas para administração da comercialização. O programa também incluiu o debate das leis que regem o uso do território nas Resex e dos programas dos diversos níveis de governo que podem ser acessados para aprimoramento da produção e incremento de renda ${ }^{24}$.

Outro exemplo fundamental da formação para gestão foi o apoio à formação de quadros para as associações. A experiência de execução dos primeiros projetos obtidos pelas associações, por exemplo, criou pendências de prestação de contas que dificultaram o acesso a novos projetos e financiamentos. Isso deixou claro que era preciso investir na formação dos moradores para a gestão, tanto do território como dessas novas formas institucionais que vivenciavam. Em 2008 foi organizado um curso de capacitação em Associativismo para as lideranças locais, incluindo representantes da Amora, Amoreri e também da Associação dos Moradores do Médio Xingu (Amomex), que representa os moradores da Reserva Extrativista Rio Xingu, criada três anos depois das outras (decreto $\mathrm{s} / \mathrm{n}^{\circ}$ de 05 de junho de 2008).

Mais recentemente, destacam-se a finalização do primeiro inventário cultural da Terra do Meio (ISA, 2017b), elaborado com participação de pesquisadores beiradeiros, a formação para pesquisa colaborativa (parceria entre associações locais e o ISA para a realização de pesquisas e sistematização de patrimônios de saberes que melhorem a gestão do território e a qualidade de vida), e a realização do magistério extrativista, iniciativa da UFPA que, pela primeira vez, leva às reservas extrativistas um curso modular de ensino médio para a formação de professores para o ensino fundamental menor ${ }^{25}$.

\subsection{Respeito aos modos de vida}

Todos os aspectos técnicos envolvidos na estruturação de associações, nos arranjos produtivos locais e na formação de pessoas só têm êxito se respeitarem os modos de vida tradicionais, encontrando respaldo nas práticas tradicionais de modo que as famílias se reconheçam e se engajem nessas estruturas e processos.

Do ponto de vista de uma instituição parceira, as ações elementares no respeito aos modos de vida são falar abertamente sobre as escolhas e implicações de qualquer ação e estar aberta para ouvir as perspectivas locais, o que não é uma tarefa simples. Ela depende de um entendimento detalhado dos modos de vida, da história de ocupação, das redes de relações, enfim, de uma compreensão de quem são as famílias e como veem o território e suas relações além. Isso implica em um entendimento historicamente óbvio, mas que nem sempre é aplicado, de que as reservas extrativistas estão sobrepostas a territórios tradicionais, com regras de gestão e relações com mercados muito mais antigas. As reservas, como resultado de lutas históricas do campesinato amazônico, têm uma razão de desenvolvimento social com respeito aos modos de vida locais. As pessoas que lutaram por elas devem ter poder de decisão e influência sobre seus rumos. É preciso

\footnotetext{
${ }^{24}$ Ao fim de cada módulo do curso era produzido um caderno de memórias e estudos para os estudantes que resumia os debates do módulo e continha exercícios para serem trabalhados pelos alunos nos entremódulos. Esses cadernos, ainda não publicados, podem ser obtidos em contato com a equipe do ISA.

${ }^{25}$ Com o magistério extrativista também se vislumbra que, em alguns anos, moradores das Resex cursem o ensino superior na UFPA, campus de Altamira, que tem cursos voltados à educação no campo e cotas para extrativistas e indígenas.
} 
romper a compreensão das reservas extrativistas apenas como unidades de conservação regidas por leis federais, uma vez que elas estão sobrepostas a territórios tradicionais muito mais antigos e com direitos consuetudinários. Com base nesses vários direitos, os moradores desses territórios negociaram e seguem a negociar com o Estado a gestão para a conservação. O sucesso das reservas extrativistas depende da garantia de voz e ação aos ocupantes tradicionais desses territórios onde hoje se encontram as unidades de conservação.

$\mathrm{Na}$ estruturação das cadeias, por exemplo, os extrativistas participam ativamente em todas as fases de debate e decisão. Retomando o exemplo da parceria comercial com a Mercur, ela resultou no primeiro termo de cooperação da região, um tipo específico de contrato pelo qual se definem as condições da relação comercial e o papel dos diferentes atores envolvidos na promoção e monitoramento das cadeias de valor. $\mathrm{O}$ termo celebra o entendimento entre as partes, considerando em especial os princípios norteadores da estruturação das cadeias e as ações previstas para consolidar a relação em longo prazo. A partir da série de encontros e debates, chegou-se ao reconhecimento de que a produção é feita em bases tradicionais e que as empresas devem respeitar a autonomia decisória e as múltiplas atividades praticadas pelas famílias, sem estipular mínimos de entrega da produção. Para os beiradeiros, a elaboração do termo significou dimensionar melhor os interesses de todos os atores do processo, aprimorando seu processo de tomada de decisão e, consequentemente, aumentando o protagonismo das comunidades nas negociações. Do lado das empresas, o entendimento mínimo da outra ponta da cadeia possibilitou também a compreensão de especificidades da forma de produção, do modo de vida e cultura em que o produto está envolvido, bem como a forma e a razão das demandas das famílias ${ }^{26}$.

Outro aspecto do respeito aos modos de vida é levar em consideração a organização e política específicas de comunidades tradicionais da Amazônia. Isso significa entender os mecanismos de gestão dos territórios, de bens comuns e de bens privados. Aprender as noções locais de justiça e de redistribuição (Almeida \& Pantoja, 2004). É fundamental compreender as formas locais de justiça e gestão e que comunidades tradicionais não são expressões do comunismo primitivo, a inversão do que achamos de nossa própria sociedade competitiva e individualista. No interior das comunidades há tensões, disputas, propriedade privada, cálculos racionais, ações morais específicas etc. Entender o funcionamento e gestão dos territórios, meios de produção e comercialização foi a base para pensar o sistema de cantinas e os detalhes de sua estruturação.

Também é preciso compreender e respeitar as dinâmicas das economias domésticas e as variações de estratégia de manutenção que cada grupo familiar adota (Almeida, 1986). Uma das importâncias de um arranjo comercial com múltiplos produtos é possibilitar estratégias de acordo com as preferências dos membros de cada casa. Por exemplo, enquanto algumas famílias preferem trabalhar na borracha, cujas seringueiras produzem com cons-

\footnotetext{
${ }^{26}$ Um exemplo desse tipo de entendimento é sobre o envolvimento das crianças nas atividades produtivas. A princípio, as empresas tendem a ver a participação de crianças no extrativismo como trabalho infantil, enquanto que, para os extrativistas, trata-se de condição de sociabilização e formação das crianças, uma das formas de reprodução dos modos de vida. Mais exemplos de negociações entre empresas e famílias podem ser encontrados na publicação Xingu (ISA, 2017a).
} 
tância e permitem planejar o orçamento doméstico com bastante segurança, outras preferem atividades com maior incerteza, mas que podem gerar rendas maiores, como a extração de copaíba. Grandes grupos domésticos ainda podem destinar seus membros a diferentes atividades. Uma família com filhos já crescidos pode se dividir entre várias atividades, aproveitando diferentes ambientes florestais para incrementar sua renda.

Respeitar os modos de vida também significa valorizar as práticas e tradições locais, dando sentido positivo a aspectos do modo de vida que sofrem constrangimentos e preconceitos no contexto regional. O Curso de Gestão teve muitos momentos de debate sobre a identidade dos beiradeiros, como lembra o relato de um dos participantes:

Antes eu tinha vergonha de dizer que eu era ribeirinho,
porque achava que ribeirinho era nada, mas fazia isso
porque não tinha pensado no seu valor. Quando eu
comecei a pensar na história dos meus avós e dos meus
pais, entendi o valor do ribeirinho. Onosso valor ésaber
o que sabemos e o que temos. [...] Há muito tempo tra-
balhamos na mata com uma inteligência muito grande,
tirando sustento do rio, da floresta. Isso pra nós é muito
valioso e serve também para conquistar nossos direitos.
O curso ajudou a mudar a forma de organização, hoje
existem as associaçóes, e a perceber a diferença entre
cuidar só da sua familia e passar a tomar conta do ter-
ritório maior: a Resex e a bacia do Xingu (Herculano
Camilo de Oliveira Filho, "Louro").

\subsection{Apoio financeiro}

Para efetuar o acesso a direitos básicos em áreas tão distantes dos centros urbanos, também foi fundamental o papel das organizações que apoiaram financeiramente as iniciativas implementadas na última década, com destaque para a Rainforest da Noruega, o Fundo Vale, a Fundação Moore, o
Environmental Defense Fund, e mais recentemente, Fundo Amazônia e a União Europeia. Em geral refratárias a respaldar ações que estão no escopo de deveres do Estado, tais entidades compreenderam que o desafio consiste justamente em criar um modelo de assistência que pudesse atrair as políticas públicas, mas de forma adaptada às realidades diferenciadas em questão.

Outra fonte de recursos que financiou diversas ações no território foi o PDRSX (Plano de Desenvolvimento Regional Sustentável do Xingu). As associações de moradores das três reservas extrativistas acessaram, por meio de editais, recursos para educação, saúde, organização comunitária, infraestrutura e atividades produtivas, totalizando mais de seis milhões de reais em 14 projetos aprovados entre 2011 e 2017. O acesso a esses recursos em tantos projetos só foi possível devido ao aprendizado da linguagem de projetos e gestão, assessoria técnica do ISA, aliados a uma visão estratégica do território e das ações prioritárias para melhoria das condições de vida.

\subsection{Políticas públicas}

Entre os propositores de leis e políticas e a execução nas comunidades, há uma variedade de atores envolvidos na garantia de direitos básicos e diferenciados para povos tradicionais. Por exemplo, a luta pela criação de polos comunitários e núcleos descentralizados também foi um processo de firmar convênios com as secretarias municipais de Altamira para que assumissem o funcionamento e a manutenção desses locais. Esse arranjo ainda está em consolidação, mas se sabe que a sustentabilidade de uma assistência de qualidade em áreas 
remotas depende de políticas públicas articuladas e diferenciadas assentadas no território. A prefeitura de Altamira, por exemplo, resistia à contratação de enfermeiros para as reservas, tanto pelos salários diferenciados como número de famílias atendidas, alegando que os repasses de recursos para o município eram insuficientes já que a presença dos beiradeiros no município não significava repasses maiores. Tentando resolver esse impasse, o ISA apoiou uma proposta de saúde diferenciada em nível nacional, apresentada ao Ministério da Saúde, e que originou uma portaria sobre as Equipes de Saúde da Família Ribeirinha ${ }^{27}$.

No que tange à estruturação das cadeias para produtos tradicionais, há políticas públicas que podem ser acessadas e beneficiam as comunidades, embora com gargalos importantes. Um dos exemplos é a Declaração de Aptidão ao Programa Nacional de Agricultura Familiar (DAP), que atesta legalmente a ligação de uma família com a agricultura familiar e permite acessar políticas públicas de apoio à produção. Em grande parte dos municípios amazônicos o procedimento para a emissão da DAP é desconhecido. Não é raro que as instituições responsáveis levem anos para emitir uma DAP para uma família solicitante, e dessa maneira todas as políticas de apoio à produção extrativista ficam completamente bloqueadas.

No caso da Terra do Meio há leis tributárias estaduais que criam outros entraves para o extrativismo, e mesmo para políticas federais de incentivo da sociobiodiversidade. Na produção de borracha, por exemplo, os seringueiros não conseguiam aces- sar o PGPM-bio por causa da Pauta Estadual da borracha ${ }^{28}$. Por anos a pauta da borracha foi maior do que o preço mínimo pago pelo PGPM-bio aos seringueiros, o que onerava injustificadamente a produção de uma cadeia produtiva que apesar de ser ambientalmente importante não consegue competir com seus similares convencionais.

Apesar das dificuldades, os extrativistas têm se articulado para acessar políticas para sua produção. Após três anos de trabalhos voltados para satisfazer as exigências legais, por exemplo, conseguiram acessar o mercado institucional do Programa Nacional de Alimentação Escolar e passaram a fornecer farinha de babaçu para os municípios de Altamira e Vitória do Xingu. Também conseguiram acessar por meio do Programa de Aquisição de Alimentos recurso para formação de estoque de farinha de babaçu para garantir o fornecimento mensal para as escolas.

Em relação à gestão das unidades de conservação em si, o Snuc representou uma mudança na compreensão das reservas extrativistas e de sua gestão, consolidando um modelo no qual os conselhos deliberativos se sobrepuseram às associações como instância decisória na gestão territorial, sendo que os conselhos são presididos pelo órgão ambiental responsável pelas reservas, antes o Ibama e atualmente o ICMBio. A criação do ICMBio e sua atuação nos anos iniciais, por sua vez, aumentou a ênfase nas políticas de conservação em detrimento das políticas de desenvolvimento para povos tradicionais. Foram diminuídas as coordenações de desenvolvimento dos povos tradicionais (como

\footnotetext{
${ }^{27}$ Trata-se da portaria n. ${ }^{\circ}$ 837/2014, que redefine o arranjo organizacional das Equipes de Saúde da Família Ribeirinha (ESFR) e das Equipes de Saúde da Família Fluviais (ESFF) dos municípios da AmazôniaLegal e do Pantanal sul-mato-grossense.

${ }^{28}$ A pauta é um instrumento de oneração fiscal que visa a combater a evasão fiscal determinando o valor mínimo para a emissão de nota fiscal para determinado produto.
} 
o CNPT) e a atuação do órgão concentrou-se na formalização das áreas a partir do estabelecimento dos chamados instrumentos de gestão previstos no Snuc e em leis complementares, planos de manejo, constituição de conselhos deliberativos, criação do perfil do beneficiário, CCDRU etc. Muitas vezes esses processos foram feitos sem o tempo devido, acarretando em mobilizações parciais no plano local e que atropelaram os tempos de compreensão e decisão das comunidades (Almeida \& Rezende, 2013).

O modelo como o ICMBio local estava estruturado (com gestores de cada unidade de conservação da Terra do Meio, priorizando e implementando ações próprias e particulares em cada unidade) criava uma gestão desintegrada, em descompasso com a forma como as comunidades estavam se organizando produtivamente e politicamente. Recentemente, o ICMBio tem reestruturado equipes em locais com mais de uma unidade de conservação, dividindo os servidores por áreas de atuação ao invés de unidades de conservação. Esse pode ser um avanço na gestão de territórios como a Terra do Meio, pois permite adotar políticas comuns que dialoguem com ações e decisões de povos e comunidades que têm continuidade no território e atuação integrada. O contingente de servidores também é claramente insuficiente para cuidar de tantos assuntos e em uma área tão grande.

Na proteção territorial também há muito a se avançar. Nos últimos anos a Reserva Extrativista Riozinho do Anfrísio tem sofrido com roubo de madeira por parte de invasores oriundos do município de Trairão e adjacências, o que vem dilapidando e degradando as florestas ao mesmo tempo em que acaba por corromper relações locais, ao criar cisões internas quanto à presença de madeireiros na região. Isso porque o Estado não tem uma estrutura de fiscalização que de fato proteja essas Resex; em alguns casos, madeireiros representam o acesso a bens e serviços que o próprio Estado não fornece, como, por exemplo, a manutenção de pequenas estradas utilizadas para deslocamentos no verão. As ações realizadas para coibir esses saques têm sido pontuais, o que tem colocado em risco a floresta e as redes de relações tradicionais (ISA, 2015).

\section{Considerações finais}

A maioria das propostas de desenvolvimento econômico para a Amazônia tem se assentado em pressupostos arcaicos que levaram a diversas formas de opressão e violência direcionadas a povos e comunidades tradicionais. Nas últimas décadas, ficou mais evidente, todavia, que essa forma de "desenvolvimento" carrega consigo não somente prejuízos diretos a esses grupos, como também impacta o planeta como um todo.

A resistência dos povos indígenas e tradicionais tem-se feito presente ao longo de todo esse processo, sendo a Aliança dos Povos da Floresta um exemplo de que esses povos não apenas recusavam as intervenções pretendidas sob o pretexto de desenvolvimento como propunham uma forma própria de pensar mudanças e intervenções para melhoria de suas realidades. Entre outras coisas, o movimento apontava para o reconhecimento dos territórios desses povos e comunidades e de seu modo de vida, para o qual a floresta e os rios lhes eram fundamentais. Defesa da floresta porque ela é condição de existência. Além disso, lutavam para que fossem conjugadas ações de acesso a saúde, educação e renda. 
Sobre o aspecto da renda, em particular, o movimento luta contra a retórica onipresente de que o modelo hegemônico de ocupação em curso é o único economicamente viável. Permanência no território, com geração de renda e a floresta em pé, é vista ainda como algo absolutamente utópico. Essa visão da vida na floresta como sinônimo de atraso - enquanto agronegócio, latifúndio, gado, madeira e grandes obras seguem associados a progresso permanece, para muitos, bastante atual. Esse entendimento, incentivado pelos segmentos econômicos interessados, traduz-se em apoio a políticas públicas vinculadas a esse "desenvolvimento" concentrador e predatório.

Na Terra do Meio, vemos como se atualiza a resistência de seringueiros, indígenas e outros povos e comunidades tradicionais, ao lado de pequenos agricultores, irmanados no questionamento a essas políticas e a esses tipos de intervenção. Mesmo diante de décadas de abandono por parte do Estado, esses grupos tomam a dianteira como arquitetos de alternativas.

E não é só contra uma visão desenvolvimentista que as comunidades têm que se organizar. Há uma outra vertente de atores que preconiza que "a comunidade precisa ser autônoma em suas conquistas". Um balanço das iniciativas na Terra do Meio aponta também que se, por um lado, o protagonismo da comunidade é o fim e fundamento de qualquer trabalho dessa natureza, não há construção possível sem alianças, apoios, assessorias técnicas, recursos, formação, intercâmbios etc. O mito da comunidade "de mãos dadas em círculo" resolvendo sozinha questões para as quais ela não está preparada ou não tem domínio completo acaba sendo um posicionamento irresponsável por parte de governo e parceiros. Vários beiradeiros manifestam-se sobre isso da seguinte maneira: os ricos e poderosos da cidade, quando precisam resolver alguma coisa, procuram um advogado, um administrador, um contador, um gerente; nós, não, nós temos que fazer tudo sozinhos - por quê? Como fica claro no caso de outras experiências na Amazônia, mas também na Terra do Meio, o protagonismo e autonomia vicejam também quando as alianças, assessorias e apoios cumprem seu papel, não só tecnicamente, mas com posições políticas claras e com diálogo franco, baseado na confiança, que só pode ser construída em uma relação longa e duradoura, sem vitimização ou paternalismo.

Nesse sentido, quando se fala em ações coordenadas em várias frentes para garantir a viabilidade social, econômica e ecológica das reservas extrativistas, fica claro que a composição de um corpo técnico-político que caminhe rumo ao protagonismo é essencial. São lideranças, cantineiros, assessores das associações, membros da diretoria que, formados nesse processo, têm sido fundamentais para o desenvolvimento e manutenção das atuais conquistas.

A formação de um corpo técnico local é fundamental para superar os vários desafios que surgem com a consolidação das reservas extrativistas e, em especial, das cadeias de produtos florestais como condição de renda e permanência das famílias no território. Embora esteja se consolidando um modelo produtivo bastante próximo às demandas das comunidades tradicionais (com multicontratos de longo prazo, bonspreços, condições diferenciadas nas relações comerciais, beneficiamento de produtos e um conjunto de cantinas com capital de giro próprio para fazer rodar a produção local), há diversos riscos ainda colocados a esse arranjo, sendo o principal deles a sustentação de um preço diferenciado do produto no longo prazo (que não seja somen- 
tefundamentado no convencimento de empresas e consumidores sobre os valores dos produtos da floresta e os modos de vida tradicionais). Devem ser desenvolvidos mecanismos de pagamento por serviços socioambientais vinculados à produção comercializada de forma que cada quilo de borracha, castanha e óleos que saírem da floresta resultem em um adicional de remuneração na mão de quem produz. Outra saída é via inovação tecnológica, desenvolvendo produtos que só possam ser produzidos com matérias-primas e conhecimentos locais. Outro desafio é a gestão de cantinas comunitárias frente ao crescimento do número de produtos e volumes comercializados, o que aumenta a complexidade e necessidade de sistemas e assessorias técnicas mais especializadas.

Além desses desafios postos para moradores e organizações locais, há ações essenciais que só podem ser garantidas pelo Estado. O extrativismo, a exemplo de outros setores da economia, necessita de investimentos, incentivos e assistência para se desenvolver - a exemplo do próprio agronegócio que recebe bilhões de financiamento todos os anos-, necessita que haja uma política forte e clara dos governos de valorização das florestas e das populações que as protegem. Também só o Estado pode prover a vigilância constante dos territórios e a proteção contra invasores. Se tais ações não forem aprimoradas, as comunidades seguirão vulneráveis contra poderes externos ilegais, hoje principalmente associados a atividades predatórias como extração madeireira e grilagem, e que, muitas vezes, utilizam de força para invadir territórios tradicionais, dilapidar as florestas e corromper relações locais. Políticas públicas de educação e saúde devem também ser melhor adaptadas e apropriadas às realidades locais, seguindo diretrizes da Política Nacional de Desenvolvimento
Sustentável dos Povos e Comunidades Tradicionais (Decreto 6040, de 07 de fevereiro de 2007) e da lei do Sistema Nacional de Unidades de Conservação (Lei 9985, de 18 de julho de 2000).

\section{Referências}

Alarcon, D. F.; Torres, M. G. 'Não tem essa lei no mundo, rapaz!'A Estação Ecológica da Terra do Meio e a resistência dos beiradeiros do alto rio Iriri. São Paulo/Altamira: Instituto Socioambiental/Associação dos Moradores da Reserva Extrativista Riozinho do Anfrísio, 2014.

Allegretti, M. Extractive reserves: an alternative for reconciling development and environmental conservation in Amazonia. In: Anderson, A. (Ed.). Alternatives to deforestation: steps toward sustainable use of the Amazon rainforest. New York: Columbia University Press, p. 252-264, 1990.

Allegretti, M. A construção social de políticas públicas: Chico Mendes e o movimento dos seringueiros. Desenvolvimento e Meio Ambiente, 18, 39-59, 2008.

Almeida, M. W. B. Redescobrindo a família rural. Revista Brasileira de Ciências Sociais, 1(1), 66-83, 1986.

Almeida, M. W. B. Rubber tappers of the upper Juruá river, Brazil: the making of a forest peasant economy. Tese de Doutorado. University of Cambridge, 1992.

Almeida, M. W. B. Direitos à floresta e ambientalismo: os seringueiros e suas lutas. Revista Brasileira de Ciências Sociais, 19(55), 34-53, 2004.

Almeida, M. W. B. As colocações: forma social, sistema tecnológico, unidade de recursos naturais. Mediações, 17(1), 121-152, 2012.

Almeida, M. W. B.; Pantoja, M. C. Justiça local nas Reservas Extrativistas. Raizes, $23(1 \mathrm{e}$ 2), 2004.

Almeida, M. W. B.; Rezende, R. S. Uma nota sobre comunidades tradicionais e unidades de conservação. RURIS-Revista do Centro de Estudos Rurais-UNICAMP, 7(2), 2013.

Castillo, C. A. "Gestão das Reservas Extrativistas". In: Murrieta, J. R.; Rueda, R. P. (Ed.). Reservas extrativistas. 


\section{IUCN, 1995.}

Costa, E. M. L. Uma floresta politizada: relações políticas na Reserva Extrativista do Alto Juruá, Acre (1994-2002). Tese de doutorado. IFCH/Unicamp, 2010.

Hecht, S. B.; Cockburn, A. The fate of the forest: developers, destroyers and defender of the Amazon. New York: Harper Collins, 1990.

Homma, A. K. O. Extrativismo vegetal ou plantio: qual a opção para a Amazônia? Estudos avançados, 26(74), 2012.

IMAFLORA; ISA. Avaliação econômica das principais cadeias de produtos da sociobiodiversidade da Resex Riozinho do Anfrísio. Disponível em https://www.imaflora. org/downloads/biblioteca/Relatorio_Anfrisio.pdf(checado em 03/2018), 2010a.

IMAFLORA; ISA. Avaliação econômica das principais cadeias de produtos da sociobiodiversidade da Resex Rio Iriri. Disponível em https://www.imaflora.org/downloads/ biblioteca/Relatorio_Iriri.pdf(checado em 03/2018), 2010 b.

IMAFLORA; ISA. Avaliação econômica das principais cadeias de produtos da sociobiodiversidade da Resex Rio Xingu. Disponível em http://www.euvotopiracicaba.org.br/ downloads/biblioteca/relatorio_xingu_terradomeio_imaflora_isa.pdf (checado em 03/2018), 2010c.

ISA - INSTITUTO SOCIOAMBIENTAL. Projeto realização de estudos preliminares e formulação de uma proposta técnica para a implantação de um mosaico de unidades de conservação no Médio Xingu. Brasília: ISA/MMA, 2003.

ISA - INSTITUTO SOCIOAMBIENTAL. Apoio ao Desenvolvimento da Comercialização de Produtos Florestais Não Madeireiros (PFNM) na Resex Riozinho do Anfrísio, Altamira - Pará. Relatório, 2008.

ISA - INSTITUTO SOCIOAMBIENTAL. Rotas do saque: violações e ameaças à integridade territorial da Terra do Meio (PA). São Paulo, 2015.

ISA - INSTITUTO SOCIOAMBIENTAL. Xingu: histórias dos produtos da floresta. São Paulo, 2017a.

ISA - INSTITUTO SOCIOAMBIENTAL. Terra do Meio/ Xingu: os saberes e práticas dos beiradeiros do Rio Iriri e Riozinho do Anfrísio. São Paulo: Instituto Socioambiental.
Disponível em: https://www.socioambiental.org/pt-br/blog/ blog-do-xingu/livro-registra-saberes-e-praticas-dos-beiradeiros-da-terra-do-meio (checado em 03/2018), 2017 b.

Lima, F. F. O acesso às politicas públicas por populações tradicionais na gestão de unidade de conservação de uso sustentável: o caso das Reservas Extrativistas da Terra do Meio, Altamira-PA. Dissertação de mestrado. Instituto Nacional de Pesquisa da Amazônia, 2015.

Pantoja Franco, M. C. Seringueiros e cooperativismo: o fetichismo das 'mercadorias' nos seringais do Alto Juruá. In: Assentamentos rurais: uma visão multidisciplinar. Editora da UNESP, 1994.

Postigo, A. de A. "Não é bom viver com quem a gente não conhece": relações sociais e suas práticas no contexto de implementação das Reservas Extrativistas da Terra do Meio. Relatório. Altamira: Instituto Socioambiental, 2012.

Rezende, R. S. Das colocações à vila: processos de urbanização no Alto Rio Tejo, Acre. Dissertação de Mestrado. IFCH/Unicamp, 2010.

Schwartzman, S. Extractive reserves: the rubber Tappers' strategy for sustainable use of the Amazon rainforest. In: Browder, J. (Org.). Fragile lands of Latin America: strategies for sustainable development, Washington, Westview Press, pp. 151-163, 1989.

Schwartzman, S. et al. The natural and social history of the indigenous lands and protected areas corridor of the Xingu River basin. Philosophical Transactions of the Royal Society B: Biological Sciences, 2013. doi: 10.1098/rstb.2012.0164

Velásquez, C.; Villas Boas, A.; Schwartzman, S. Desafio para a gestão ambiental integrada em território de fronteira agrícola no oeste do Pará. Revista de Administração Pública-RAP, 40(6), 2006.

Weinstein, B. A borracha na Amazônia: expansão e decadência 1850-1920. São Paulo: Hucitec/Editora da Universidade de São Paulo, 1993. 